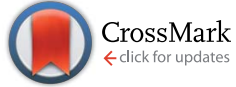

Cite this: RSC Adv., 2015, 5, 50328

\title{
Conducting polyaniline based cell culture substrate for embryonic stem cells and embryoid bodies
}

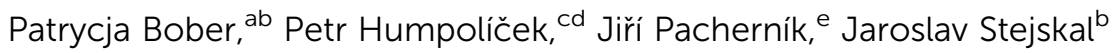 \\ and Tom Lindfors ${ }^{* a}$
}

In this work, thin films consisting of electrically conducting polyaniline (PANI) and poly(2-acrylamido-2methyl-1-propanesulfonate) (PAMPSA) have been used as cell culture substrates for embryonic stem cells (ESC) and embryoid bodies (EMB). The PANI-PAMPSA films having fibrillar morphology were electrochemically polymerized in a single-step by cyclic voltammetry from an aqueous solution containing aniline and PAMPSA. UV-visible spectroscopy showed that the PANI films were electrically conducting still at $\mathrm{pH}$ 10. This makes them suitable for tissue engineering applications operating at physiological $\mathrm{pH}$, in contrast to the commonly used PANI hydrochloride films which loose their electrical conductivity at $\mathrm{pH} \geq 4$. Our results reveal that the PANI-PAMPSA films allow only for limited ESC adhesion and growth. The inhibition of the EMB growth and adhesion on the PANI-PAMPSA surface in serum-free medium indicates that it can be used as a cell-selective substrate for the growth of only some specific differentiated EMB cell types.

Received 24th April 2015 Accepted 29th May 2015

DOI: $10.1039 / c 5 r a 07504 a$

www.rsc.org/advances

\section{Introduction}

Conducting polymers are usually composed of organic semiconducting macromolecules but they may also show metallic conductivity. Polyaniline (PANI), polypyrrole and poly(3,4ethylenedioxythiophene) (PEDOT) are examples of such polymers. ${ }^{\mathbf{1} 2}$ In addition to their conductivity, they possess the ability to respond to various external stimuli affecting their optical, electrical, chemical, and mechanical properties. Polyaniline is one of the most studied conducting polymers due to its high electrical conductivity, excellent electronic and optical properties, good redox and ion-exchange activity, environmental stability, ease of preparation from common chemicals, and low cost. ${ }^{3}$ PANI exists in a variety of forms, ${ }^{3,4}$ differing in the degree of oxidation or extent of protonation and thus affecting its chemistry. The most important form of PANI, the protonated emeraldine salt (ES), can be obtained by the polymerization of aniline in acidic aqueous media. ${ }^{3}$ It is green, stable and electrically conducting having usually a conductivity $\sigma \approx 4 \mathrm{~S} \mathrm{~cm}^{-1} \cdot{ }^{5}$ With increasing the $\mathrm{pH}$, the ES form converts typically at $\mathrm{pH} \geq 4$ to the

\footnotetext{
å̊bo Akademi University, Johan Gadolin Process Chemistry Centre, Faculty of Science and Engineering, Laboratory of Analytical Chemistry, FIN-20500 Turku, Finland. E-mail: Tom.Lindfors@abo.fi

${ }^{b}$ Institute of Macromolecular Chemistry, Academy of Sciences of the Czech Republic, 16206 Prague 6, Czech Republic

${ }^{c}$ Tomas Bata University in Zlin, Centre of Polymer Systems, 76005 Zlin, Czech Republic ${ }^{d}$ Tomas Bata University in Zlin, Faculty of Technology, Polymer Centre, 76272 Zlin, Czech Republic
}

${ }^{e}$ Masaryk University Brno, Faculty of Sciences, Institute of Experimental Biology, 625 oo Brno, Czech Republic electrically non-conducting emeraldine base form (EB) with a conductivity of $\sigma \approx 10^{-9} \mathrm{~S} \mathrm{~cm}^{-1}$. Hence, it is clear that the ESEB transition limits the use of PANI in applications requiring high level of conductivity over a broad $\mathrm{pH}$ range. For example, in biomedical applications operating at the physiological $\mathrm{pH}=7.4$, it is necessary that PANI stays in the electrically conducting form at neutral and slightly alkaline $\mathrm{pH}$. Various approaches have been used to solve this problem. The loss of the acid counter-ion in PANI-ES at higher $\mathrm{pH}$ may be reduced by using polymeric acids, e.g., poly(2-acrylamido-2-methyl-1-propanesulfonic acid) (PAMPSA), ${ }^{6}$ contributing to the $\mathrm{pH}$-stability of the ES form up to pH 10 (Fig. 1). Another approach is to use hydrophobic acids, such as perfluorooctanesulfonic $\mathrm{acid}^{7}$ or dodecylbenzenesulfonic acid keeping PANI in the ES form up to $\mathrm{pH} 8$ and 9, respectively. Self-doped sulfonated PANI represents still another materials category extending the stability of the ES form to the neutral pH region., ${ }^{\mathbf{9} 10}$

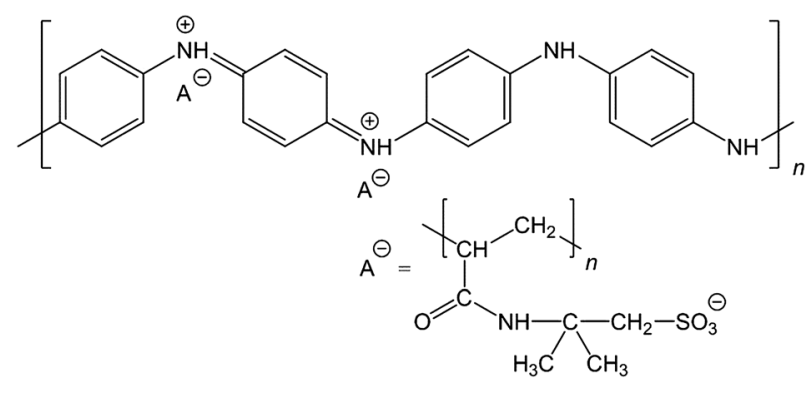

Fig. 1 The chemical structure of the PANI-PAMPSA complex. 
Polyaniline can be prepared by chemical or electrochemical polymerization of aniline. With the latter method it is possible to precisely direct the PANI film formation on small electrically conducting substrates (e.g., electrode arrays) which can then be used, for example, as the ion-to-electron transducer in all-solidstate ion-selective electrodes. ${ }^{11-13}$ The electropolymerization of aniline has usually been carried out in aqueous solutions containing inorganic acids, e.g., sulfuric acid, ${ }^{\mathbf{1 4 - 1 6}}$ perchloric acid, ${ }^{15}$ nitric acid,,$^{\mathbf{1 4}}$ or phosphoric acid, ${ }^{17}$ or in solutions of organic acids, e.g., $p$-toluenesulfonic acid. ${ }^{18}$ It can also be done in the presence of polymeric acids such as poly(styrenesulfonic acid) ${ }^{\mathbf{1 9}}$ or PAMPSA, ${ }^{20-24}$ and also in organic solvents, e.g., acetonitrile $^{25-27}$ or dichloromethane. ${ }^{27}$

In the last decade, we have observed a growing interest in the use of conducting polymers in biological and biomedical applications, including cardiac and neural tissue engineering, drug delivery, and biosensors. ${ }^{28-35}$ Polypyrrole has successfully been applied in drug delivery, ${ }^{28,29,36}$ nerve regeneration ${ }^{31}$ and biosensors. $^{32,34}$ PEDOT-gelatin composites have recently been tested as new biocompatible substrates in tissue engineering. ${ }^{35}$ Jin et $a l .{ }^{37}$ demonstrated that PEDOT nanofibers have similar biocompatibility as tissue culture (TC) plates. Cheng et al. $^{33}$ showed that PEDOT-carbon nanotube composites improve the biocompatibility of platinum electrodes implanted into rat brain. The toxicity of PEDOT-heparin surfaces have been investigated by Asplund et al. ${ }^{30}$

The relatively high conductivity of PANI in combination with its good environmental stability have led to an investigation of its applicability in tissue engineering, especially for the tissues sensitive to electrical properties, such as neuronal lineage differentiation, ${ }^{38}$ myoblast differentiation, ${ }^{39}$ and cardiomyocyte synchronization. ${ }^{\mathbf{4 0}}$ The knowledge of biomedical properties of pristine PANI is surprisingly limited as the most studies deal with PANI composites or copolymers. Nevertheless, it was reported that the PANI in powder form, prepared according to "standard" procedure, ${ }^{5}$ does not provoke the skin irritation or sensitization. ${ }^{41}$ However, the cytotoxicity observed in the same study outlined the limits of PANI in biomedical engineering. Wang et $a{ }^{42}$ reported good cell compatibility of PANI films prepared by direct deposition during the polymerization, and doped by perchloric, hydrochloric, malic, or citric acid. On the other hand, the corresponding films prepared by solution casting showed limited cell adhesion. ${ }^{42}$ The colloidal PANI dispersions, prepared with poly( $N$-vinylpyrrolidone) as stabilizer, had dose-dependent cytotoxicity, but at sufficiently low non-cytotoxic concentrations, the colloids were free of an immune response. ${ }^{43}$ The PAMPSA used as counter-ion in this study was reported to act against blood clotting ${ }^{\mathbf{4 4 , 4 5}}$ and activation of serum complement activity, ${ }^{46}$ which both are important factors with impact on biocompatibility.

Compared to the conventional chemical oxidative polymerization, the electropolymerization offers a simple method to obtain well-defined polymer films without the need of removing undesired by-products from the polymer film after the polymerization. The surface morphology of the films and their thickness can be easily controlled. In this study, we have grown electrochemically prepared PANI-PAMPSA films on glass substrates and studied the growth and adhesion of embryonic stem cells (ESC) and embryoid bodies (EMB) on the film surfaces. The application of any material in tissue engineering is mostly focusing on the stem cells and, to the best of our knowledge, the compatibility of the PANI-PAMPSA films with ESC and EMB has not been previously reported. The ESC and EMB in this work represent starting materials for the preparation of a variety cell types. The results are therefore crucial for practical use of conducting PANI in biomedical engineering.

\section{Experimental}

\subsection{Electropolymerization of aniline}

Both aniline and PAMPSA (molecular weight $\approx 2000000$; $15 \mathrm{wt} \%$ aqueous solution) were purchased from Sigma-Aldrich and used as received. The electropolymerization of $0.05 \mathrm{M}$ aniline was carried out in an oxygen-free aqueous solution of $0.3 \mathrm{M}$ PAMPSA (calculated on the basis of the repeating constitutional units) by continuously cycling the potential between -0.7 and $0.9 \mathrm{~V}$ for $5,10,15,20$ and 25 cycles with the scan rate of $50 \mathrm{mV} \mathrm{s}^{-1}$. The tin-oxide (TO) glass served as the working electrode while a glassy-carbon rod and a calomel electrode $(3 \mathrm{M} \mathrm{KCl})$ have been used as the counter and reference electrodes, respectively. In all measurements, the potential was controlled either with an Autolab PGSTAT 20 or 100 potentiostat. All solutions were purged with nitrogen gas for $30 \mathrm{~min}$ prior to the electropolymerization and blanketed with nitrogen during the polymerization. After the electropolymerization, the PANI-PAMPSA films were characterized by cyclic voltammetry in monomer- and oxygen-free 0.3 M PAMPSA solutions with the scan rates of 10, 20, 50, 100 and $200 \mathrm{mV} \mathrm{s}^{-1}$.

\subsection{UV-vis spectra}

The UV-vis spectra of the PANI-PAMPSA films were recorded in UV-vis buffer solutions of pH 2-12 (ref. 63) with a Lambda 25 spectrometer (Perkin Elmer, UK) by placing the TO glasses with the deposited polymer films in a polystyrene cuvette perpendicularly to the incident light-beam of the spectrophotometer. The buffer solutions consisted of $0.0225 \mathrm{M}$ solutions of citric acid (monohydrate) ( $\geq 99.5 \%$ ), Tris (p.a. $\geq 99.8 \%$ ), $\mathrm{KCl}$ (p.a. $\geq$ 99.5\%), obtained from Fluka, $\mathrm{KH}_{2} \mathrm{PO}_{4}$ and $\mathrm{Na}_{2} \mathrm{~B}_{4} \mathrm{O}_{7} \cdot 10 \mathrm{H}_{2} \mathrm{O}$ were from Merck, and the $\mathrm{pH}$ was adjusted in the individual buffer solutions by adding either $\mathrm{HCl}$ or $\mathrm{NaOH}$ solutions. In the UV-vis measurements, a syringe was used to manually fill the sample cuvettes with buffer solution and to remove the previous solution. UV-vis spectra were recorded every third minute during $30 \mathrm{~min}$ at each $\mathrm{pH}$.

\subsection{Scanning electron microscopy and water contact angles}

The scanning electron microscope (SEM) LEO 1530 Gemini FEG-SEM was used to study the surface morphology of the PANI-PAMPSA films and the water contact angle (CA) measurements were carried out with the KSV CAM 200 goniometer (KSV instruments). For the EB form of PANI, the water CAs were measured after deprotonation of the film with $1 \mathrm{M}$ ammonium hydroxide. 


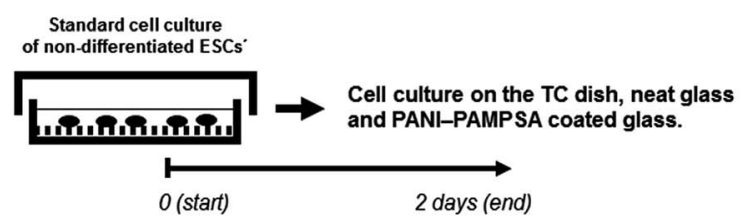

EMBs adhesion and growth

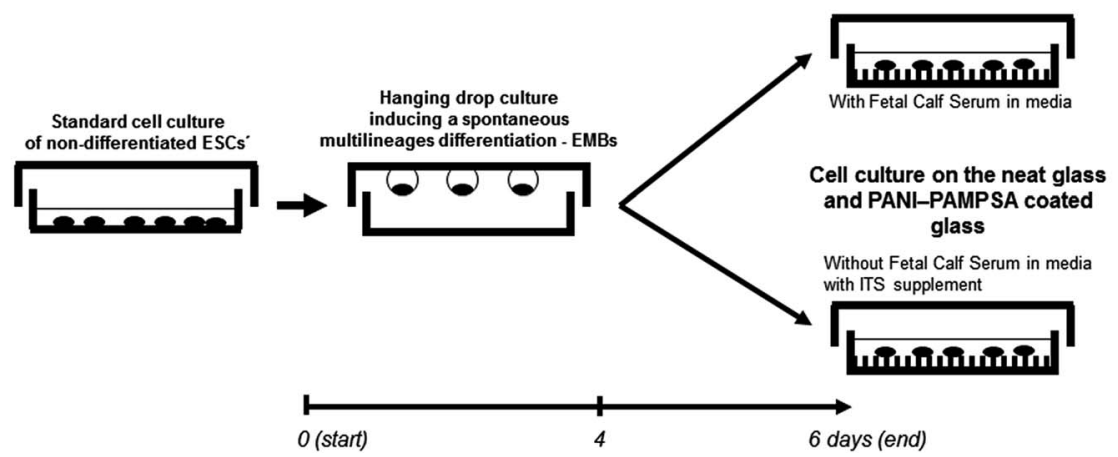

Scheme 1 The experimental design of the cell-compatibility test.

\subsection{Adhesion and growth of embryonic stem cells and embryoid bodies}

Prior to in-vitro testing, the surface of the PANI-PAMPSA films were disinfected by 30 min exposure to an UV-radiation source operating at the wavelength of $258 \mathrm{~nm}$. To detect the cell adhesion and growth, two cell types have been used: (1) nondifferentiated embryonic stem cells (ESC), namely the widely used pluripotent mouse embryonic stem cell line R1 derived from inner cell mass of mouse blastocyst, first isolated by Nagy et $a .^{64}$ (ATCC, SCRC-1011 ${ }^{\mathrm{TM}}$ ) and (2) embryoid bodies (EMB) differentiated from the above-defined ESC. The ESC were maintained and differentiated through the formation of the EMB as previously described. ${ }^{59,65}$ In practise, the ESCs was propagated in an undifferentiated state by culturing them in Dulbecco' modified Eagle' medium, high glucose (Gibco-Invitrogen) supplemented with $15 \%$ foetal calf serum (Gibco-Invitrogen), $100 \mathrm{mM}$ non-essential amino acids (Gibco-Invitrogen), $0.05 \mathrm{mM}$ $\beta$-mercaptoethanol (Sigma-Aldrich, St. Louis, MO), $100 \mathrm{U} \mathrm{ml}^{-1}$ penicillin, $0.1 \mathrm{mg} \mathrm{\textrm {ml } ^ { - 1 }}$ streptomycin (GibcoInvitrogen), and $1000 \mathrm{U} \mathrm{ml}^{-1}$ recombinant leukaemia inhibitory factor (LIF; Merck-Millipore) referred here as the ESC media.

The differentiation of the ESCs were then realized by elimination of LIF from the cultivation media and by the formation of the EMBs using the hanging drop technique ( 400 cells per drop, $30 \mu \mathrm{l})$. Four days old EMBs were seeded to the tested material in the ES media without LIF or in serum-free media, DMEM-F12 (1:1) media supplemented with insulin, transferrin, selenium (ITS, Gibco-Invitrogen), and antibiotics (as above).

At first, the compatibility was studied for the ESCs seeded on the tissue-culture dishes (TPP, Switzerland), neat glass, and the PANI-PAMPSA coated glass substrates. For testing the ES cell growth, $3 \times 10^{4}$ cells per $\mathrm{cm}^{2}$ was seeded and cultured in ESC media for two days (Scheme 1). In the second parallel experiment, the four days old EMBs $\left(10\right.$ EMBs per $\left.\mathrm{cm}^{2}\right)$ were seeded as describe above in serum or serum-free media. The cell morphology was then examined after 24 and 48 h by using a digital camera and an inverted microscope (CKX 41 Olympus, Japan) in both experiments (Scheme 1). All the tests were repeated 3 times, with at least two samples in every repetition.

\section{Results and discussion}

\subsection{Electrosynthesis and electrochemical characterization of the PANI-PAMPSA films}

PANI-PAMPSA films prepared by electropolymerization of aniline in the presence of PAMPSA have been previously reported. ${ }^{20-24}$ In those studies, however, the polymerization was carried out in aqueous electrolytes containing more than one acid which makes it possible that several acid anions will be incorporated as counter-ions in the PANI matrix during the electropolymerization. ${ }^{\mathbf{6} 21}$ It was shown by Łapkowski that aniline can be successfully electropolymerized on platinum in a pure PAMPSA solution. ${ }^{20}$ By following this procedure, we have obtained PANI films protonated exclusively with PAMPSA counter-ions which were incorporated as a polyelectrolyte complex in the polymer matrix during the electropolymerization. The PANI-PAMPSA film formation on the TO glass substrate was monitored by recording the cyclic voltammograms (CV) during the electropolymerization in the aqueous solution of $0.05 \mathrm{M}$ aniline and 0.3 M PAMPSA (Fig. 2). Two characteristic oxidation and reduction peaks can be clearly distinguished in the CV of the thinner PANI-PAMPSA films prepared with 5 and 10 potential cycles. The first redox peak is assigned to the leucoemeraldine to ES transition and the 
second to the ES to pernigraniline salt transition. ${ }^{\mathbf{2 3 , 4 7}}$ It should be noted that the ES form is the only electrically conducting form of PANI. These two transitions in the CV are associated with the colour changes from colorless to green and green to blue which makes it easy to visually distinguish between the different oxidation/protonation states of the PANI-PAMPSA film. By increasing the numbers of potential cycles to 15, 20 and 25 during the electropolymerization, the peak currents increased gradually indicating that the thickness of the PANIPAMPSA film depends on the applied potential cycles. Moreover, the higher separation of the oxidation and reduction peaks indicates that the electron transfer in the polymer film becomes more sluggish in thicker PANI-PAMPSA films due to the higher degree of cross-linking disrupting the $\pi$-conjugation resulting in the decrease in electrical conductivity.

After the electropolymerization, the PANI-PAMPSA films were characterized with CV in monomer- and oxygen-free $0.3 \mathrm{M}$ PAMPSA solution at the scan rates of $10-200 \mathrm{mV} \mathrm{s}^{-1}$ (Fig. 3). The increase in the current density at $E>0 \mathrm{~V}$ (with a maximum at $0.45 \mathrm{~V}$ ) in the $\mathrm{CV}$ measured with $50 \mathrm{mV} \mathrm{s}^{-1}$ (Fig. 3A) indicates that the film was converted from the non-conducting leucoemeraldine form to the electrically conducting ES form. When

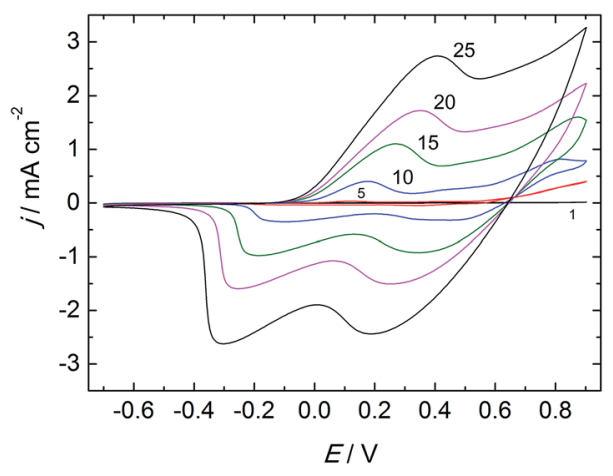

Fig. 2 The cyclic voltammograms recorded during the electropolymerization of $0.05 \mathrm{M}$ aniline in the aqueous solution of $0.3 \mathrm{M}$ PAMPSA. The 1, 5, 10, 15, 20 and 25th polymerization cycles are shown; scan rate: $50 \mathrm{mV} \mathrm{s}^{-1}$. the potential was reversed, the PANI-PAMPSA film is converted back to the leucoemeraldine form and displays a characteristic reduction peak at $-0.26 \mathrm{~V}$. The oxidation and reduction peaks correspond to the charging and discharging of the PANIPAMPSA film and it was therefore possible to control the oxidation state (i.e. also the conductivity) of the polymer film by the applied potential. This property makes the PANI-PAMPSA film attractive as a cell culture substrate where the electrical impulses can be used as external stimuli for initiating and promoting the cell growth. The CV response of PANI-PAMPSA is stable without degradation during 10 potential cycles (Fig. 3A) thus enabling a fast switching of the oxidation state of the polymer film. As shown in Fig. 3B, the PANI-PAMPSA film can be switched between the non-conducting and conducting states also at higher scan rates. However, the peak separation increased with the scan rate which is typical for conducting polymers with kinetically limited quasi-reversible electron transfer.

Characterization of the PANI-PAMPSA films by SEM reveals a globular and open-surface morphology with the pore size of $c a$. 100-200 nm (Fig. 4A and B). The water CA measurements show that the ES form of the PANI-PAMPSA film is very hydrophilic having a CA of $18^{\circ}$ (Fig. 4C), which is considerably lower than for the PANI hydrochloride films $\left(42^{\circ}\right){ }^{48,49}$ After deprotonation, the water CA of the PANI-PAMPSA film increased to $53^{\circ}$ (Fig. 4D) due to the uncharged polymer backbone, but this is still much lower than typically reported values for the EB form of PANI, $82^{\circ}-$ $94^{\circ} .^{48,50,51}$ Although the surface morphology and porosity may influence the water CA, this suggests that the strongly hydrophilic PAMPSA counter-ions are still associated with the PANI backbone even after deprotonation in alkaline media in $1 \mathrm{M}$ ammonium hydroxide, possibly by physical entrapment.

\subsection{UV-vis spectroscopy}

The UV-vis spectra of the PANI-PAMPSA film recorded between pH 2-12 are shown in Fig. 5. The spectrum of PANI-PAMPSA at $\mathrm{pH} 2$ has two absorption maxima typical for the ES form at $413 \mathrm{~nm}$ and above $c a .800 \mathrm{~nm}^{4}$ assigned to the $\pi-\pi^{*}$ transition
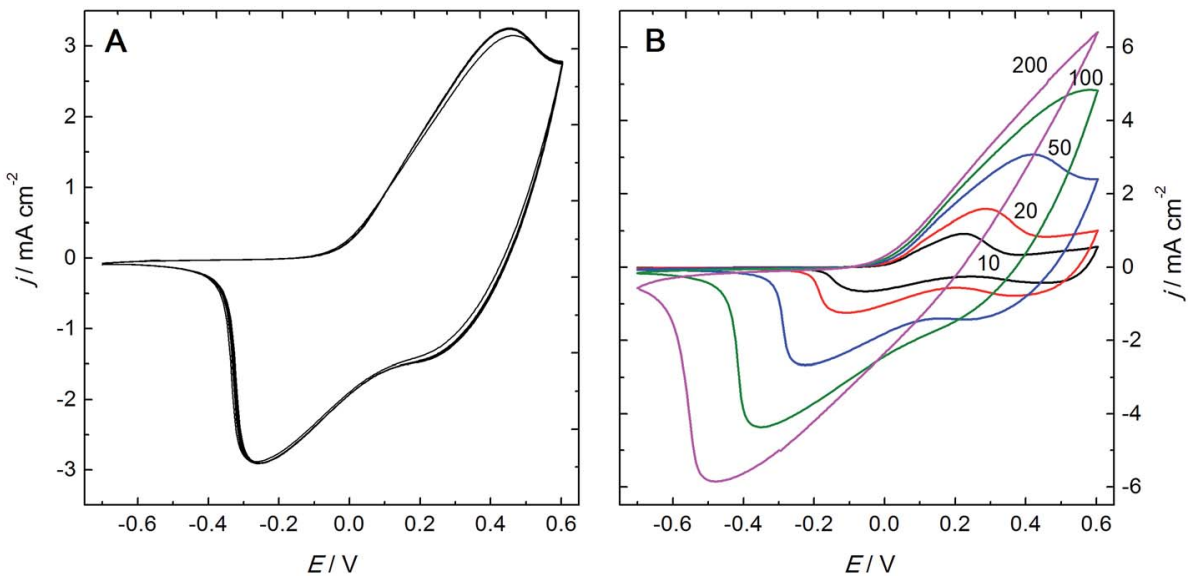

Fig. 3 The cyclic voltammograms of the PANI-PAMPSA film in an aqueous solution of 0.3 M PAMPSA. (A) 10 potential cycles measured with the scan rate of $50 \mathrm{mV} \mathrm{s}^{-1}$, and (B) characterization with different scan rates: 10, 20, 50, 100, and $200 \mathrm{mV} \mathrm{s}^{-1}$. 


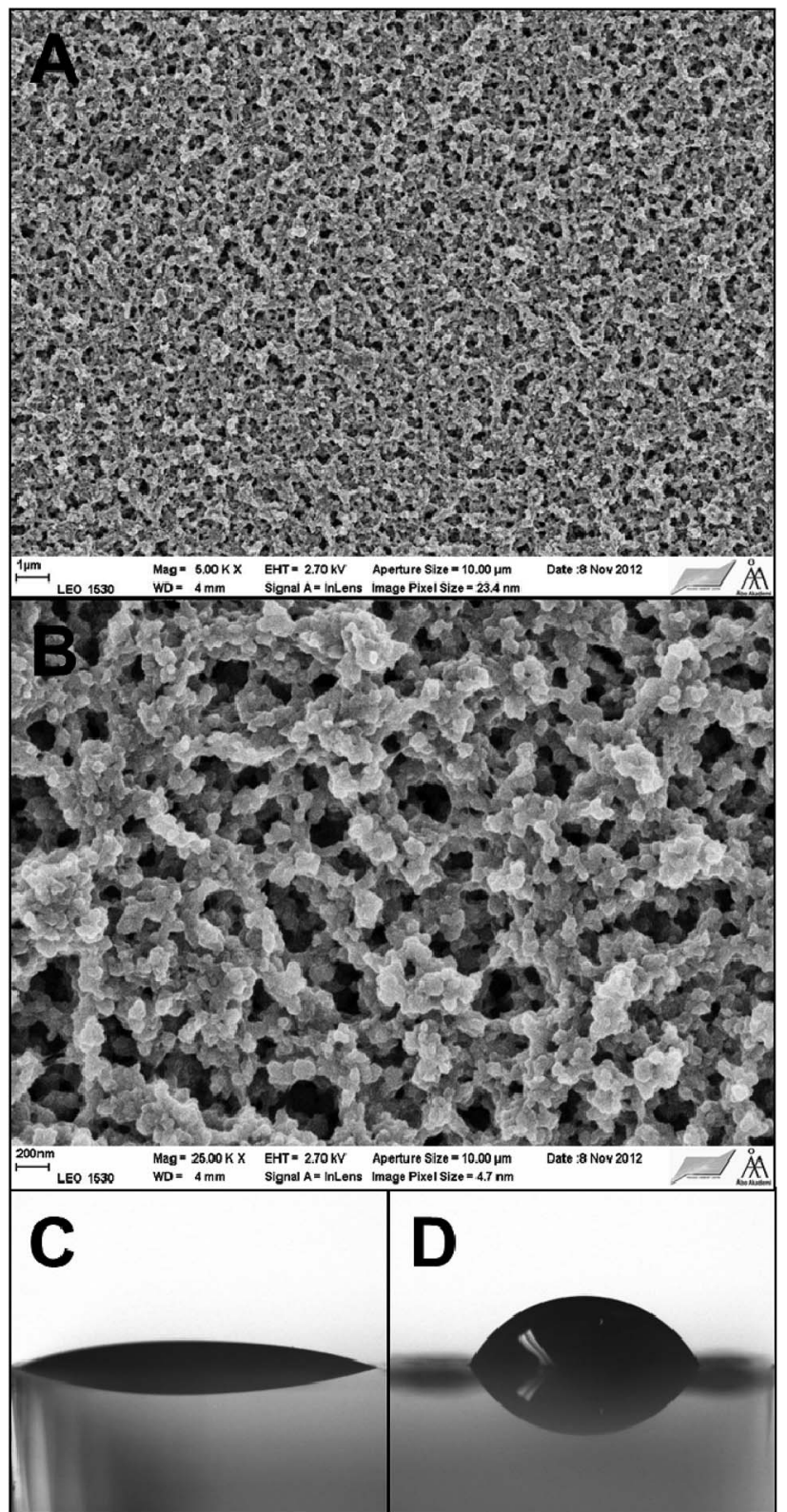

Fig. 4 SEM images of the PANI-PAMPSA film taken with the magnifications $5000 \times(\mathrm{A})$ and $25000 \times(\mathrm{B})$ The water CA of the PANIPAMPSA films in the ES (C) and EB (D) forms.

of the benzenoid rings and the polaron band transitions, respectively. ${ }^{52}$ Most of the PANI-PAMPSA film is in the ES form still at $\mathrm{pH}$ 10. The gradual conversion from the ES to EB form takes place only at $c a$. $\mathrm{pH}>10$ and the absorption maximum at $651 \mathrm{~nm}$ corresponding to the $n-\pi^{*}$ exciton transition of the quinonoid rings confirm that the PANI-PAMPSA film is entirely in the EB form at $\mathrm{pH} 12 . .^{52}$ The reason for the very good stability of the ES form of PANI-PAMPSA in alkaline solutions is that the PAMPSA counter-ions cannot be easily removed from the PANI backbone due to the interpolymer complex formation between PANI and PAMPSA..$^{53}$ This was confirmed by the energy dispersive X-ray analysis (EDAX) revealing the presence of $3.3 \mathrm{wt} \%$ and $4.3 \mathrm{wt} \%$ sulfur (originating from PAMPSA) in the ES ( $\mathrm{pH} 2$ ) and
EB (pH 12) forms of the PANI-PAMPSA film, respectively. It is likely that the negatively charged PAMPSA counter-ions make it energetically favorable for the protons to stay attached to the PANI backbone even under alkaline $\mathrm{pH}$, and therefore enhancing the $\mathrm{pH}$ stability of the ES form of the PANI-PAMPSA films. Clearly, the high pH stability of PANI-PAMPSA makes it attractive in applications requiring electrical conductivity and operation at the physiological $\mathrm{pH}$.

\subsection{Adhesion of embryonic stem cells and embryoid bodies}

The information about the cell and tissue compatibility of materials are crucial for their application in biomedical engineering. It has been reported that the leucoemeraldine, emeraldine, and pernigraniline forms of PANI show good tissue compatibility. ${ }^{54,55}$ A better cell growth and adhesion for PC-12 pheochromocytoma cells was obtained for in situ polymerized PANI films, compared to drop-casted films, probably due to their different nanoscale morphology. ${ }^{42}$ Recently, the ability of HepG2 cells to grow and attach on the PANI-ES and PANI-EB surfaces was studied for films prepared according to the procedure recommended by IUPAC., ${ }^{5,56}$ However, the ES to EB transition of these PANI films take place at $\mathrm{pH} \cong 6$ limiting their practical applications at the physiological $\mathrm{pH}$. The PAMPSA has been shown to act against blood clotting either alone ${ }^{44}$ or incorporated in copolymers, ${ }^{45}$ and it also inhibits the activation of serum complement activity ${ }^{46}$ The favorable properties of PAMPSA in combination with the good stability of the ES form of PANI-PAMPSA even at $\mathrm{pH} 10$ opens new possibilities for the application of PANI at the physiological $\mathrm{pH}$. We have therefore studied the adhesion and growth of the ESCs and EMBs on the PANI-PAMPSA film surfaces. Only the fibroblast (NIH 3T3 cell line) adhesion on PANI-PAMPSA has been previously investigated, but on films prepared by chemical oxidative polymerization on electrically non-conducting substrates hindering electrical stimulation of the cell growth. ${ }^{57}$

The ESCs form usually relatively flat and compact colonies within $48 \mathrm{~h}$ after seeding provided that they are seeded on the TC dishes without the feeder-cell layers. We have therefore used this approach to study the cell growth and adhesion on neat glass and the PANI-PAMPSA surfaces without using feeder

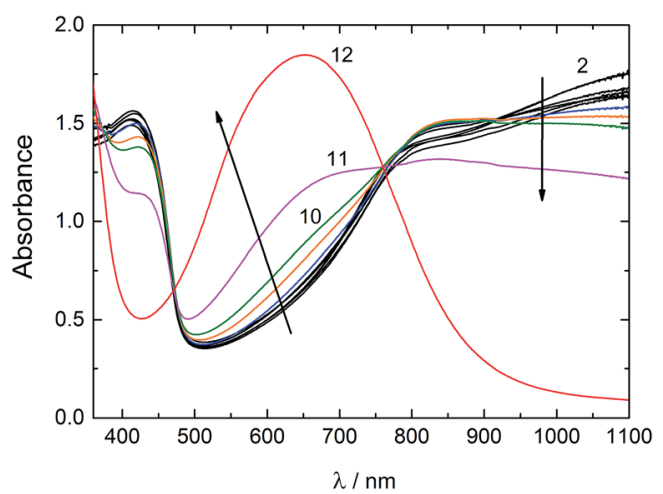

Fig. 5 UV-vis spectra of the PANI-PAMPSA films recorded in buffer solutions between $\mathrm{pH} 2-12$. 


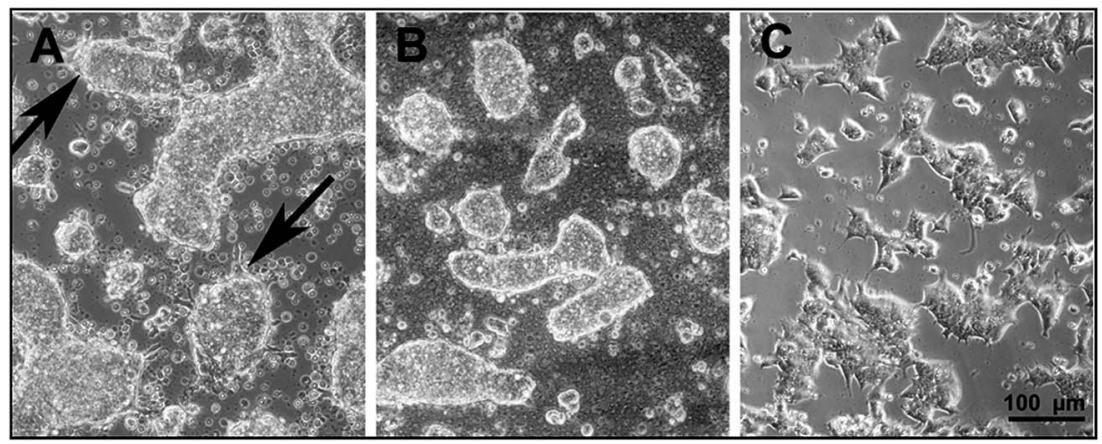

Fig. 6 The surface morphology of the embryonic stem cells grown for $48 \mathrm{~h}$ on the (A) glass substrate, (B) PANI-PAMPSA-coated glass, and (C) on the polystyrene tissue-culture dish. The arrows indicate the protrusion of the rare cells present on glass, which are not observed in the embryonic stem cells on the PANI-PAMPSA film.

layers. Our results show that on the neat glass surfaces, the ESC form 3-D spheroid-like colonies which adhere to the substrate but have a limited spreading over it (Fig. 6A). The same behavior was also observed on the glass substrate coated with the PANIPAMPSA film which further decreased the spreading of the ESCs (Fig. 6B). Moreover, numerous floating single cells and probably apoptotic bodies (markers for the apoptotic form of cell death, see ref. 58 for more information) were observed on the PANIPAMPSA surface, in contrary to the TC dishes having a very low content of them (Fig. 6C). This indicates that the ESC are able to adhere on the PANI-PAMPSA but their growth conditions are unfavorable. Hence, it can be concluded that the PANI-PAMPSA surface is not suitable for the growth and expansion of the ESC which only form 3-D colonies. It is therefore expected, that the ESC pluripotency is also affected. Based on the changes in the morphology of the cells and its colonies, we conclude that the PANI-PAMPSA substrate induced stress on the ESCs (as mentioned above). The maintenance of the pluripotency and self-renewal is a tightly regulated feature of the ESCs. We therefore suggest that the conditions that induced the stressed ESC morphology are not optimal for the maintenance of the pluripotency and self-renewal of the ESCs, which are the two key features of this cell type.

The behavior of four days old EMB was also studied on the neat glass and the PANI-PAMPSA-coated glass substrates (Fig. 7). The EMB consisted of various cell types differentiated from the ESC. Different protocols used for the preparation of numerous specific cells from ESC employ the formation of EMB as an initial and general differentiation step. The EMB provide therefore insight into the cell compatibility for tissue engineering purposes. Our results reveal that both in the presence and absence of fetal calf serum in the cultivation medium, the adhesion of EMB was better on the neat glass (Fig. 7A and B) than on the glasses coated by PANI-PAMPSA (Fig. 7C and D). It is known that proteins present in the serum have generally a positive impact on cell adhesion. ${ }^{59,60}$ It was thus expected that the cell adhesion will be better in the presence of serum.

Surprisingly, in the culture medium with the serum, the EMB did not adhere to PANI-PAMPSA while in its absence some of the EMB were slightly attached. It was also observed that the cells on the periphery of the EMB expanded rapidly under the serum-free condition. This is in contrast with the seeding of the EMB on TC dishes where EMB expanded faster in presence of serum. ${ }^{59}$ The presence and absence of serum also influenced the cell differentiation. The ectoderm cells preferentially differentiated in absence of serum. ${ }^{61,62}$ It can be speculated that the better cell expansion of cells in the absence of serum can therefore be connected with the higher differentiation of EMB cells to cell types for which PANI-PAMPSA can be a suitable substrate. However, a more extensive study is required to confirm this hypothesis.

In summary, the result presented here show that the electropolymerized PANI-PAMPSA films, which retain the electrical conductivity up to $\mathrm{pH} 10$, can be used as a cell culture substrate in tissue engineering. Our measurements reveal that the PANIPAMPSA films allow limited ESC adhesion and growth on its
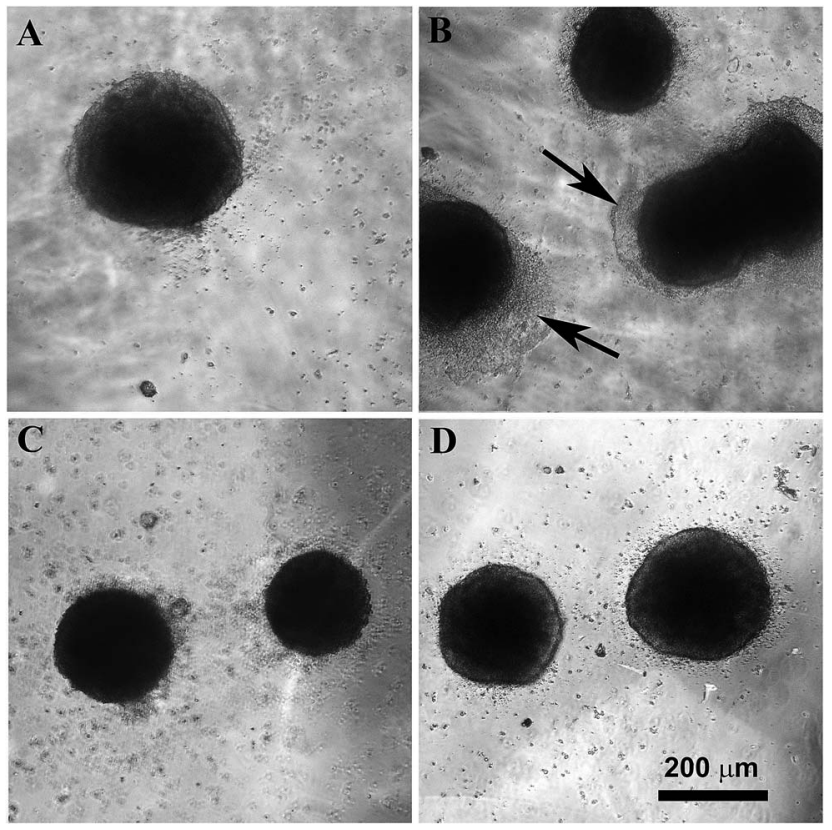

Fig. 7 The embryoid bodies grown on glass in the presence (A) and in the absence (B) of serum, and on glass coated with PANI-PAMPSA in the presence $(C)$ and in the absence $(D)$ of serum. The arrows mark the expanded cells from the adhered embryoid bodies. 
surface. These results outline that without surface modification (e.g. immobilization of some bioactive substances) the PANIPAMPSA film is not an appropriate choice for tissue engineering techniques using the ESC cells. On the other hand, the very promising behavior of inhibiting the cell growth and adhesion of the EMB on the PANI-PAMPSA surface in serum-free medium indicates the presence of specific interactions of PANI-PAMPSA with some cell types present in EMBs. This interaction may be used for preferential cell selection in the differentiation processes used for the ESC.

\section{Conclusions}

We show in this paper that electrochemically prepared PANIPAMPSA films are non-cytotoxic. They can be used as cell culture substrates at the physiological $\mathrm{pH}$ due to the excellent stability of the electrically conducting form of PANI-PAMPSA even at $\mathrm{pH}$ 10. It is demonstrated for the embryoid bodies that only some cell types were able to grow on the surface of the PANI-PAMPSA film. The possibility of precisely depositing the PANI-PAMPSA film by electropolymerization on small surfaces, in combination with further functionalization of the film surface, opens new directions in designing PANI-PAMPSA based cell culture substrates having selective interaction with specific target cells. The strongly limited cell growth and adhesion on the PANI-PAMPSA surface may find application areas in implantable solid-state chemical sensors and other implantable devices.

\section{Acknowledgements}

Financial support from the Johan Gadolin Scholarship Programme (P.B.) within the Johan Gadolin Process Chemistry Centre at Åbo Akademi University (Finland), the Academy of Finland (projects 130588 and 263656), and the Czech Science Foundation (13-08944S) are gratefully acknowledged.

\section{References}

1 A. Pron and P. Rannou, Prog. Polym. Sci., 2002, 27, 135.

2 A. J. Heeger, Chem. Soc. Rev., 2010, 39, 2354.

3 A. G. MacDiarmid and A. J. Epstein, Faraday Discuss., 1989, 88, 317.

4 J. Stejskal, P. Kratochvíl and A. D. Jenkins, Collect. Czech. Chem. Commun., 1995, 60, 1747.

5 J. Stejskal and R. G. Gilbert, Pure Appl. Chem., 2002, 74, 857. 6 V. V. Lyutov, S. D. Ivanov, V. M. Mirsky and V. T. Tsakova, Chem. Pap., 2013, 67, 1002.

7 P. Bober, T. Lindfors, M. Pesonen and J. Stejskal, Synth. Met., 2013, 178, 52.

8 T. Lindfors and A. Ivaska, J. Electroanal. Chem., 2002, 531, 43. 9 J. Yue and A. J. Epstein, J. Am. Chem. Soc., 1990, 112, 2800.

10 J. Yue, Z. H. Wang, K. R. Cromack, A. J. Epstein and A. G. MacDiarmid, J. Am. Chem. Soc., 1991, 113, 2665.

11 T. Lindfors and A. Ivaska, Anal. Chem., 2004, 76, 4387.

12 T. Lindfors, H. Aarnio and A. Ivaska, Anal. Chem., 2007, 79, 8571.
13 T. Lindfors, J. Szucs, F. Sundfors and R. E. Gyurcsanyi, Anal. Chem., 2010, 82, 9425.

14 G. Zotti, S. Cattarin and N. Comisso, J. Electroanal. Chem., 1988, 239, 387.

15 G. Sandi and P. Vanysek, Synth. Met., 1994, 64, 1.

16 M. Blomquist, J. Bobacka, A. Ivaska and K. Levon, J. Solid State Electrochem., 2012, 16, 2783.

17 A. Eftekhari and R. Afshani, J. Polym. Sci., Part A: Polym. Chem., 2006, 44, 3304.

18 J. L. Camalet, J. C. Lacroix, S. Aeiyach and P. C. Lacaze, J. Electroanal. Chem., 1998, 445, 117.

19 D. S. Lin, C. T. Chou, Y. W. Chen, K. T. Kuo and S. M. Yang, J. Appl. Polym. Sci., 2006, 100, 4023.

20 M. Łapkowski, Synth. Met., 1993, 55, 1558.

21 V. V. Lyutov, G. Georgiev and V. Tsakova, Thin Solid Films, 2009, 517, 6681.

22 A. A. Nekrasov, O. L. Gribkova, T. V. Eremina, A. A. Isakova, V. F. Ivanov, V. A. Tverskoj and A. V. Vannikov, Electrochim. Acta, 2008, 53, 3789.

23 O. L. Gribkova, A. A. Nekrasov, M. Trchová, V. F. Ivanov, V. I. Sazikov, A. B. Razova, V. A. Tverskoy and A. V. Vannikov, Polymer, 2011, 52, 2474.

24 O. L. Gribkova, A. A. Nekrasov, V. F. Ivanov, V. I. Zolotorevsky and A. V. Vannikov, Electrochim. Acta, 2014, 122, 150.

25 K. Kanamura, S. Yonezawa, Y. Kawai and Z.-I. Takehara, J. Electroanal. Chem. Interfacial Electrochem., 1991, 301, 291.

26 F. Fusalba and D. Belanger, J. Phys. Chem. B, 1999, 103, 9044.

27 P. C. Pandey and G. Singh, J. Electrochem. Soc., 2002, 149, D51.

28 Y. J. Li and S. D. Dong, J. Chem. Soc., Chem. Commun., 1992, 1, 827.

29 K. Kontturi, P. Pentti and G. Sundholm, J. Electroanal. Chem., 1998, 453, 231.

30 M. Asplund, E. Thaning, J. Lundberg, A. C. SandbergNordqvist, B. Kostyszyn, O. Inganäs and H. von Holst, Biomed. Mater., 2009, 4, 045009.

31 G. Kang, R. B. Borgens and Y. N. Cho, Langmuir, 2011, 27, 6179.

32 J. C. Soares, A. Brisolari, V. da Cruz Rodrigues, E. Aparecido Sanches and D. Gonçalves, React. Funct. Polym., 2012, 72, 148.

33 X. Cheng, C. Y. Li, L. Rao, H. H. Zhou, T. Li and Y. W. Duan, J. Wuhan Univ. Technol., Mater. Sci. Ed., 2012, 27, 1053.

34 M. Foschini, A. Marletta, R. C. Faria, D. Leonard, F. Bessueille, N. Jaffrezic-Renault and D. Gonçalves, Electroanalysis, 2013, 25, 741.

35 M. Bongo, O. Winther-Jensen, S. Himmelberger, X. Strakosas, M. Ramuz, A. Hama, E. Stavrinidou, G. G. Malliaras, A. Salleo, B. Winther-Jensen and R. M. Owens, J. Mater. Chem. B, 2013, 1, 3860.

36 C. Arbizzani, M. Mastragostino, L. Nevi and L. Rambelli, Electrochim. Acta, 2007, 43, 3274.

37 L. Jin, T. Wang, Z. Q. Feng, M. K. Leach, J. H. Wu, S. J. Mo and Q. J. Jiang, J. Mater. Chem. B, 2013, 1, 1818.

38 E. A. Ostrakhovitch, J. C. Byers, K. D. O'Neil and O. A. Semenikhin, Arch. Biochem. Biophys., 2012, 528, 21. 
39 S. H. Ku, S. H. Lee and C. B. Park, Biomaterials, 2012, 33, 6098.

40 C. W. Hsiao, M. Y. Bai, Y. Chang, M. F. Chung, T. Y. Lee, C. T. Wu, B. Maiti, Z. X. Liao, R. K. Li and H. W. Sung, Biomaterials, 2013, 34, 1063.

41 P. Humpolicek, V. Kasparkova, P. Saha and J. Stejskal, Synth. Met., 2012, 162, 722.

42 H. J. Wang, L. W. Ji, D. F. Li and J. Y. Wang, J. Phys. Chem. B, 2008, 112, 2671.

43 Z. Kuceková, P. Humpolíček, V. Kašpárková, T. Perečko, M. Lehocký, I. Hauerlandová, P. Sáha and J. Stejskal, Colloids Surf., B, 2014, 116, 411.

44 D. Paneva, O. Stoilova, N. Manolova, D. Danchev, Z. Lazarov and I. Rashkov, e-Polym., 2003, 052, 1.

45 E. Yancheva, D. Paneva, D. Danchev, L. Mespouille, P. Dubois, N. Manolova and I. Rashkov, Macromol. Biosci., 2007, 7, 940.

46 H. Setoyama, Y. Murakami, K. Inoue, H. Iwata, H. Kitamura, T. Shimada, H. Kaji, Y. Ikada and M. Imamura, Transplant. Proc., 1999, 31, 2818.

47 V. V. Lyutov, V. Tsakova and A. Bund, Electrochim. Acta, 2011, 56, 4803.

48 M. J. Liu, K. Tzou and R. V. Gregory, Synth. Met., 1994, 63, 67. 49 J. Stejskal, J. Prokeš and M. Trchová, React. Funct. Polym., 2008, 68, 1355.

50 T. V. Shishkanova, I. Sapurina, J. Stejskal, V. Král and R. Volf, Anal. Chim. Acta, 2005, 553, 160.

51 N. V. Blinova, J. Stejskal, M. Trchová and J. Prokeš, Polym. Int., 2008, 57, 66.
52 A. P. Monkman and P. Adams, Synth. Met., 1991, 41, 861. 53 Z. A. Boeva, O. A. Pyshkina and V. G. Sergeev, Polym. Sci., Ser. A, 2012, 54, 614.

54 C. H. Wang, Y. Q. Dong, K. Senghoti, K. L. Tan and E. T. Kang, Synth. Met., 1999, 102, 1313.

55 S. Kamalesh, P. Tan, J. Wang, T. Lee, E. Kang and C. Wang, J. Biomed. Mater. Res., 2000, 52, 467.

56 P. Humpolicek, V. Kasparkova, J. Stejskal, Z. Kucekova and P. Sevcikova, Chem. Listy, 2012, 106, 380.

57 C. L. Bayer, I. J. Trenchard and N. A. Peppas, J. Biomater. Sci., Polym. Ed., 2010, 21, 623.

58 V. Bryja, J. Pacherník, K. Souček, V. Horvath, P. Dvořák and A. Hampl, Cell. Mol. Life Sci., 2004, 61, 1384.

59 I. Veselá, H. Kotasová, S. Jankovská, J. Procházková and J. Pacherník, Folia Biol., 2010, 4, 165.

60 E. Brynda, J. Pacherník, M. Houska, Z. Pientka and P. Dvořák, Langmuir, 2005, 21, 7877.

61 J. Pacherník, V. Bryja, M. Ešner, L. Kubala, P. Dvořák and A. Hampl, Physiol. Res., 2005, 54, 115.

62 H. Kotasová, I. Veselá, J. Kučera, Z. Houdek, J. Procházková, M. Králíčková and J. Pacherník, J. Cell. Biochem., 2012, 113, 563.

63 D. D. Perrin and B. Dempsey, Buffers for $\mathrm{pH}$ and metal ion control, Chapman and Hall, London, 1974, p. 48.

64 A. Nagy, J. Rossant, R. Nagy, W. Abramow-Newerly and C. D. Roder, Proc. Natl. Acad. Sci. U. S. A., 1993, 90, 8424.

65 G. Sustáčková, S. Legartová, S. Kozubek, L. Stixová, J. Pacherník and E. Bártová, Stem Cells Dev., 2012, 5, 710. 